\title{
ĠFORSETI
}

Forseti. Revista de Derecho. Edición de aniversario, Lima, DERUP, 2018, pp 128-142

\section{Expropiados de voluntad. Crítica al arbitraje potestativo}

\author{
Mario Pasco Lizárraga*
}

Resumen.- En el presente artículo, el autor brinda un panorama completo sobre los alcances del arbitraje laboral en el Perú, en su modalidad potestativa. Una vez identificado cuando se puede someter a un Arbitraje potestativo un conflicto sobre negociación colectiva, disiente de la tendencia doctrinaria que respalda la institución. La particularidad de su posición se sustenta en lo injusto y pernicioso que puede ser, para las partes, este método de solución de controversias laborales.

Abstract.- In the following paper, the author provides a complete overview of the scope of labor arbitration in Peru, in its optional form. Once identified when there may be a potential Arbitration that opposes a conflict that opposes collective bargaining, the author disagrees with the doctrinal tendency that supports the institution. The particularity of its position is sustainable in what is harmful and pernicious that can be, for the parties, this method of solving labor disputes.

Profesor de Derecho Laboral en la Universidad del Pacífico, Socio de Rodrigo Elías \& Medrano. 
Intentaremos, en el presente trabajo, describir algunas de las razones por las que encontramos el actual sistema de negociación colectiva en nuestro país, marcado principalmente por el denominado arbitraje potestativo, cercano a lo irracional.

Desde la década de los noventa, el Perú experimenta un crecimiento económico sostenido. Para ello, ha sido necesario que el mercado financiero y bursátil local se amolden a las circunstancias e implementen nuevas herramientas para mejorar las garantías de crédito.

\section{Introducción}

Nuestro sistema de relaciones colectivas de trabajo, en lo que a su marco legal se refiere, sufrió una transformación radical a partir del el 17 de agosto del 2009, cuando una de las salas del Tribunal Constitucional sentenció el Exp. 03561-2009-PA/TC1, y luego cuando, el 10 de junio del 2010, aclaró de oficio dicha sentencia, para precisar que el arbitraje que definiría la discusión de las partes sobre el nivel de la negociación colectiva en dicha actividad, era de carácter potestativo. Vale decir, que si una de las partes sometía el diferendo a arbitraje, la otra estaba obligada a acudir al mismo, aunque no hubieran suscrito un convenio arbitral.

A lo largo de estos últimos ocho años, la discusión al respecto no ha cesado. Se trata de una materia aún resistida, y que ha atravesado sucesivos cambios adicionales.

La sentencia, en efecto, se emitió respecto de un caso con características muy marcadas; a saber:

- No se discutía aún el fondo de la negociación, pues ésta no se había iniciado; las partes no estaban de acuerdo sobre si la negociación se llevaría a cabo con cada empleadora (como planteaban las empresas) o con todas ellas en conjunto (como impulsaba el sindicato).

- Las empresas habían venido esgrimiendo el artículo 45 de la Ley de Relaciones Colectivas de Trabajo (LRCT), conforme al cual si no había acuerdo sobre el nivel de una primera negociación colectiva, ésta se llevaría a nivel de empresa.

Seguido por el Sindicato Único de Trabajadores Marítimos y Portuarios del Puerto del Callao (Sutramporpc) contra las organizaciones empresariales que agrupaban a los empleadores de sus afiliados. 
- El Tribunal encontró inconstitucional la norma recién mencionada y, por extensión, que su uso por parte de los empresarios había sido un acto de mala fe, por lo cual procedía que se llevara a cabo un arbitraje para definir el diferendo.

- Luego, en la aclaración, agregó que dicho arbitraje sería potestativo, pues si los empresarios no designaban un árbitro a efectos de constituir el tribunal, la Autoridad de Trabajo lo haría por ellos.

Esto supuso una ruptura fundamental respecto de lo que había sido la práctica administrativa y de partes hasta ese momento. El reglamento de la LRCT determinaba que la Autoridad Administrativa de Trabajo designaría árbitro en lugar de la parte rebelde, si ésta no cumplía con hacerlo dentro de los cinco días posteriores a la suscripción del convenio arbitral, con lo cual el procedimiento se iniciaba sólo con intervención de la voluntad de ambas partes.

En otras palabras, aunque podía haber discusión teórica sobre si el arbitraje en la LRCT era potestativo o voluntario, en la práctica había sido únicamente voluntario.

Ahora bien, incluso con el parecer de una buena parte del Tribunal Constitucional volcado en dicha sentencia, la misma surtía efecto para las partes en ese proceso, no para terceros, y habría resultado en extremo debatible que la Autoridad Administrativa pasara a aplicar de modo general un procedimiento (de imposición del arbitraje por una parte a la otra) que no era el recogido en el derecho positivo.

De allí que al poco tiempo, en setiembre del 2011, el gobierno de ese entonces modificó el reglamento de la LRCT, introduciendo de modo explícito el arbitraje potestativo ${ }^{2}$ a nuestro ordenamiento. A ese efecto identificó tres escenarios en los que procedía el mismo:

- Cuando en una primera negociación las partes no se ponen de acuerdo en el nivel de la negociación colectiva.

- Cuando en una primera negociación las partes no se ponen de acuerdo en el contenido de la negociación colectiva.

- Antes actos de mala fe de una de las partes, cuyo efecto sea dilatar, entorpecer o evitar el logro de un acuerdo.

2 Existe un sector de juristas que plantea que ello no era necesario, pues en estricto el arbitraje laboral fue siempre potestativo, desde la LRCT. Véase CARRILLO, Martín. «El arbitraje laboral potestativo incausado». En: Libro Homenaje a Mario Pasco Cosmópolis. Lima, Sociedad Peruana de Derecho del Trabajo y de la Seguridad Social, 2015, p. 225. 
En la aplicación de la nueva institución se han presentado incontables controversias, derivadas principalmente de su característica principal, cual es ser un sistema descentralizado de resolución de conflictos, que carece de una entidad, persona, organismo o mecanismo que pueda establecer criterios generales.

Así, los estándares de severidad con los cuales se juzga los actos de mala fe de las partes han variado sensiblemente de un tribunal a otro, y en el plano procedimental también se han presentado criterios muy apartados entre sí al momento de establecer los procedimientos para la delimitación recién descrita, pues la misma no se encuentra determinada con precisión en la normativa ${ }^{3}$.

En lo más trascendente, han existido tribunales que -como hemos adelantado en nota a pie- han procedido a instalar y llevar a cabo el arbitraje potestativo por considerar que el mismo no requiere de causa demostrada, mientras que en otros casos se ha evaluado la existencia de las mismas, y se ha determinado como improcedente el pedido de arbitraje si, en el criterio del tribunal (o la mayoría dentro del mismo), no se había demostrado la causal recogida en la ley.

Esta última discusión ha intentado ser superada a través del Decreto Supremo 009-2017-TR, que claramente se decanta por exigir la presencia de las causales antes listadas, o del acuerdo de partes, para que proceda el arbitraje. Sin embargo, ni siquiera de esa manera ha quedado superada la incertidumbre, pues continúan apareciendo laudos, y sentencias, discrepantes.

\section{De lo que no trata este trabajo}

El arbitraje laboral, cualquiera sea su modalidad, debe su existencia a la ley, y es ésta la que lo crea, define y regula. Todas las decisiones judiciales o arbitrales sobre esta materia han constituido esfuerzos de interpretación legal, para la cual la Constitución ha operado simplemente como apoyo.

Pero lo cierto es que los órganos de interpretación legal y constitucional han dejado sentado el sistema de arbitraje potestativo, pronunciándose en el sentido de que (i) el sistema legal es de arbitraje potestativo (precisado normativamente como causado), y (ii) el sistema legal es válido constitucionalmente.

3 A pesar de que el artículo 64 de la LRCT ordena que «Las normas procesales serán idénticas para toda forma de arbitraje». 
En otras palabras, no postularemos que en el sistema vigente el arbitraje no pueda ser considerado o establecido como potestativo, pues lo cierto es que ya lo está; por obra de los órganos competentes de interpretación constitucional y legal, y por los órganos competentes de producción legislativa y reglamentaria.

Pero sí plantearemos una serie de consideraciones por las cuales encontramos que ese sistema -el sistema legal vigente de arbítrate potestativo- está mal.

\section{Por qué el arbitraje potestativo es injusto y pernicioso}

Hay una virtud innegable en el arbítrate potestativo, cualquiera sea la variante que adopte: goza de un nivel importante de respaldo entre los abogados laboralistas del Perú.

No conocemos estudios ni encuestas al respecto, pero nos atreveríamos a decir que una mayoría de nuestros colegas lo miran con buenos ojos $\mathrm{y}$, aunque en muchos casos con reservas relacionadas con defectos evidentes del mecanismo actual, lo consideran positivo.

A continuación, expondremos algunos argumentos por los que discrepamos, respetuosa pero frontalmente, de la opinión prevalente. En nuestro concepto, el arbitraje es una vía extremadamente valiosa para la solución de los conflictos colectivos de trabajo, pero siempre que sea adoptado como tal por las partes, no impuesto -en el sentido propio del término- a una de ellas.

El arbitraje debe ser -como ordena el inciso 2 del artículo 28 de la Constitución ${ }^{4}$ - promovido por el Estado a fin de que los actores sociales resuelvan pacíficamente su discrepancia, pero sin olvidar que la solución del diferendo corresponde -tanto en el fondo como en el procedimiento- al accionar conjunto de las voluntades de las partes (que no tiene que ser armonioso, sino únicamente pacífico); no a la ley ni al Estado.

Si se deja de lado este punto central, se podrá tener un método de fijación de remuneraciones, o de ordenamiento de las relaciones labo-

\footnotetext{
4 «Artículo 28.- El Estado reconoce los derechos de sindicación, negociación colectiva y huelga. Cautela su ejercicio democrático: (...)

2. Fomenta la negociación colectiva y promueve formas de solución pacífica de los conflictos laborales.

La convención colectiva tiene fuerza vinculante en el ámbito de lo concertado».
} 
rales, pero no un sistema que constituya o repose en la negociación colectiva.

Nuestros cuestionamientos principales fluyen por tres vertientes:

- Un arbitraje sin decisión de ambas partes carece de legitimidad.

- Una solución que prescinde de la identidad de las partes, no constituye una dirimencia seria del conflicto de intereses.

- El arbitraje potestativo plantea cuestiones insolubles, confirmadas en la realidad.

\section{i. No hay arbitraje sin partes}

A fin de tener una real perspectiva de lo que significa el arbitraje laboral, y de la especialísima relación entre los árbitros y las partes, es necesario recordar que la determinación que se les encarga a los primeros consiste en la dirimencia de un conflicto de intereses, no de derecho.

La diferencia, que es fundamental, es explicada con la mayor simplicidad por Pla Rodriguez:

El conflicto de derecho versa sobre la interpretación y aplicación de un derecho nacido y actual; poco importa que éste tenga su fuente de origen en la prescripción formal de una ley o en una disposición de un contrato individual o de un convenio colectivo. Ejemplo: un obrero que reclama judicialmente el pago del salario adeudado.

El conflicto de intereses, por el contrario, no versa sobre la interpretación de un derecho adquirido, fundado en la ley o en el contrato, sino sobre una simple reivindicación tendiente a modificar un derecho existente o a crear un nuevo derecho. Ejemplo: la demanda del personal exigiendo la creación de una bolsa de trabajo ${ }^{5}$.

La derivación necesaria del arbitraje laboral como uno que resuelve un conflicto de intereses, es que la solución no viene dada de antemano por el ordenamiento jurídico. No existe una ley que establezca cuánto es el aumento al que «debe» acceder un sindicato en una determinada coyuntura.

5 PLA RODRIGUEZ, Américo. «La solución de los conflictos colectivos de trabajo: Perspectiva Iberoamericana». AAVV. México, Secretaría de Trabajo y Previsión Social, 1985, p. 19. 
Esto encuentra reflejo en que el arbitraje laboral se acerque mucho más a uno de conciencia que a uno de derecho. Como explicaba Elias Mantero:

En el arbitraje de derecho los árbitros actúan de la misma forma que se produce la intervención judicial puesto que su obligación es resolver de acuerdo a lo establecido en el régimen normativo vigente. No sucede lo mismo en el caso del arbitraje de conciencia en el cual los árbitros resuelven de acuerdo con su «leal saber y entender» ${ }^{6}$.

El mismo Elias Mantero cuestionaba que el arbitraje laboral fuera en estricto de conciencia, cuando planteaba lo siguiente:

El arbitraje laboral en el Perú, establecido exclusivamente para la negociación colectiva, se afilia a ninguna de las dos formas de arbitraje enunciadas pues los árbitros no tienen la facultad de imponer una solución de acuerdo con su «leal saber y entender», como tampoco aplican normas jurídicas por no ser esta la finalidad de la negociación colectiva. Además, la aplicación de normas pre-existentes es propia de un arbitraje de derecho. En el procedimiento de negociación colectiva no estamos ante la aplicación de normas jurídicas sino ante la creación de obligaciones de contenido económico ${ }^{7}$.

Completaba su razonamiento el tan recordado autor, expresando que desde que los árbitros en un procedimiento laboral no laudan en base a su criterio únicamente, sino que están vinculados por las propuestas de solución de las partes, e incluso al elegir entre ellas, lo deben hacer en base a determinar «la más razonable y equitativa dentro de las circunstancias de la negociación colectiva de trabajo» ${ }^{8}$.

Ello no obstante, tendríamos que convenir en que, incluso eligiendo entre propuestas de partes, no existe norma ni parámetro que determine cuál y por qué una de las propuestas es la más razonable y equitativa.

De inicio, tenemos que hay cuando menos dos grupos humanos (el sindicato y quienes forman la voluntad de la entidad empleadora) con visiones opuestas al respecto.

Pero, peor aún, si se toma en cuenta la cantidad e índole de los factores a tomar en cuenta a fin de llegar a tal determinación, y la inexistencia de pesos o prioridades en los mismos, la magnitud de la

\footnotetext{
6 ELIAS MANTERO, Fernando. Relaciones Colectivas de Trabajo. Lima, Jus Editores, 1995, p. 240.

7 Idem.

$8 \quad$ Ibid. p. 243.
} 
facultad cuasi discrecional del árbitro en una negociación colectiva se potencia exponencialmente.

Simplemente como referencia, consideremos que el único condicionante -si cabe denominarlo así- que impone la LRCT a los árbitros es el que aparece en su artículo 65, conforme al cual «Para la decisión deberán tenerse presente las conclusiones del dictamen (...)» que emite la Autoridad Administrativa de Trabajo a pedido de una parte, conforme al artículo 56 de la misma norma.

Pero tener en cuenta un informe económico, el cual establece -entre muchos otros aspectos- si la Empresa ha tenido o no ganancias, a cuánto han ascendido ellas, la magnitud de la organización, el desarrollo funcional de la misma, y similares, de poco servirá, siendo que la real determinación que llevan a cabo los árbitros es eminentemente interna, personalísima, y consiste en la atribución de pesos determinados de importancia al trabajo y al capital en la actividad empresarial.

De allí que si juntamos a cualquier número de personas distintas, abogados o no, laboralistas o no, de la misma edad o condición económica o no, y las alimentamos con los datos con que cuenta un tribunal arbitral laboral para laudar, o les agregamos el doble o el triple de insumos conceptuales, el resultado será previsiblemente el mismo: tendremos el mismo número de soluciones distintas, que el número de personas en la sala.

Este carácter de determinación de conciencia -en este caso, más propiamente, de determinación subjetiva- se ve además confirmado por el artículo 65 de la LRCT, que confiere a los árbitros la potestad de atenuar posiciones extremas en su laudo, «por su naturaleza defallo de equidad».

Cuando un árbitro o tribunal resuelve una negociación colectiva, entonces, no está ilustrando a las partes sobre la verdad -al estilo de lo que hace un juez o un árbitro de derecho- sino que está sustituyendo sus voluntades.

Las posturas de las partes en la negociación colectiva, en efecto, nunca estarán «bien» ni «mal»; no habrá la correcta y la incorrecta, como que tampoco habrá un buen o mal convenio colectivo, sino llanamente un convenio colectivo. A diferencia del conflicto jurídico, cuando dos partes negocian un pliego de reclamos, ninguna «tiene razón», ambas tienen posiciones.

En efecto, mientras negocian las partes, cualquiera de ellas puede llenarse de razones y argumentos, cifras y datos, alegatos y exhorta- 
ciones. Pero nada de ello importará para que haya convenio colectivo; lo único determinante será que su voluntad, y la de la contraparte, coincidan o no, logren el acuerdo o no.

La cifra correcta, la solución verdadera para la negociación colectiva, el número mágico, es únicamente aquél al que las partes han llegado, cualquiera sea la vía que hayan utilizado, pero que haya sido propia. Recordemos que el derecho de las partes es a la negociación, no a que el aumento cubra sus aspiraciones.

Pueden estar contentas o sentirse derrotadas, terminar entusiasmadas o desencantadas, pero lo relevante será que las voluntades hayan coincidido, sea en firmar un acuerdo, pacíficamente o luego de un conflicto abierto (huelga), o entregándole la solución a un tercero, como sucede en el arbitraje voluntario.

En el arbitraje potestativo se rompe de modo irremediable este vínculo vital entre las dos partes y la solución. La historia se desencadena a lo Deus ex machina, como un mecanismo omnipotente que prescinde de la intervención de los propietarios del sistema -las partes como conjunto-, se superpone a quienes eran los protagonistas, únicos interesados y afectados, e invade el escenario con un libreto distinto, propio, ajeno a los actores reales.

La legitimidad de las amplísimas facultades de un árbitro tiene un único origen: la firma de las partes. Resulta inaudito que en un supuesto donde tales facultades son aún mayores, puedan aparecer por voluntad de tan solo una de ellas.

Adviértase que nuestro cuestionamiento al arbitraje potestativo no supone en modo alguno que estemos postulando que los actos de mala fe en que pueda incurrir una parte negocial deban ser tolerados o no tengan una consecuencia.

Las partes tienen el deber de negociar de buena fe, pues ello es sustento y componente imprescindible del derecho a la negociación colectiva. Sin embargo, el incumplimiento de ese derecho debiera ser tratado a través de los mecanismos punitivos aplicables a las infracciones laborales, o abordados a través de las consecuencias dañosas que pueda producir. El deber de negociar de buena fe es una obligación jurídica, y su incumplimiento determina un conflicto jurídico, pero no modifica el conflicto de intereses subyacente.

Por lo tanto, debe ser abordado como tal, a través de los medios aplicables a los conflictos jurídicos, y permanecer en dicha órbita, sin con- 
taminar o mezclar un ámbito con el otro, en tanto que sus lógicas y mecanismos son distintos e incompatibles entre sí. Las trasgresiones de las partes no cambian el fondo económico subyacente al conflicto.

\section{ii. La identidad de las partes}

Nuestra segunda incomodidad con el arbitraje potestativo obedece a la desconexión total presente entre la realidad de la negociación colectiva en la que se produzca aquél, y la solución a que arribe el laudo.

El convenio colectivo es el reflejo fiel de lo que las partes hayan logrado; de lo que hayan podido extraerse -en el sentido positivo de la palabra- mutuamente.

Si un sindicato es potente y actúa de modo eficaz, generará suficiente persuasión y presión para acercar el resultado a sus expectativas. De modo correlativo, si un empleador cuenta con los medios o habilidades para resistir tales esfuerzos, podrá lograr que el resultado sea más compatible con su visión de las cosas.

De modo similar a alguna de nuestras digresiones previas, lo recién dicho aplica a cualquiera de las vías a través de las cuales se llega a un convenio colectivo.

Tanto si es en negociación directa corta o compleja, o en una conciliación privada o administrativa, como también cuando el documento se firma tras una huelga que puede haber transitado por momentos de especial complejidad o delicadeza, en todos los casos el resultado será «el correcto», el que corresponda con exactitud a lo que sean y hayan hecho las partes, precisamente por el hecho simple de que ellas lo han decidido.

También aplica esta característica al arbitraje potestativo. Sea que los árbitros hayan optado por una u otra opción, e incluso si han utilizado de modo agresivo su facultad de atenuación, lo que estará ocurriendo es que en el acuerdo estará quedando reflejado que el equilibrio o situación de las partes llevaron a que optaran por ese laudo (aunque no lo hayan conocido con antelación) antes que por las otras vías que tenían a su disposición.

En el arbitraje potestativo, esa relación, que debiera ser indesligable, nuevamente se rompe.

La solución del conflicto, del pliego de reclamos, no dependerá ya de lo que es o lo que hace cada una de las partes, sino de la decisión de 
una de ellas y, una vez adoptada ésta, de la actuación de los abogados de las partes, y de los árbitros que sean designados al efecto.

Piénsese si no, simplemente, en un empleador cuyos trabajadores hayan formado más de un sindicato.

Hipotéticamente, dicho empleador podrá perfectamente llegar a un acuerdo con uno de ellos de modo precoz, pero con el otro la negociación sea más áspera; a este efecto bastará... eso: que las voluntades del empleador y un sindicato coincidan con relativa facilidad, y que entre las del mismo empleador y el otro sindicato no suceda lo mismo.

En un sistema racional de relaciones de trabajo, ello debiera determinar que, cuando se llegue a la solución con el segundo sindicato, en la diferencia de los convenios colectivos se plasme también, y de modo reconocible, la diferencia entre los sindicatos, tanto en lo que son como en lo que hicieron. Si uno de los sindicatos fue más hábil, o era más poderoso que el otro, previsible y lógicamente podrá haber conseguido un mejor resultado.

Pero cuando intervenga en la ecuación un arbitraje potestativo, cualquiera de las partes - y naturalmente cualquiera de los sindicatos podrá extraer la discusión de la esfera de los actos y posibilidades de las partes, y derivarla a tres personas que ni son las partes, ni saben lo que saben las partes, ni hacen lo que hacen las partes, ni tienen los intereses de cada una de las partes.

El laudo, en este caso, podrá dar más al sindicato más pequeño, o menos al que haya luchado más, en función a criterios en los que no habrá intervenido el empleador. Esto llega a ser presentado como una ventaja del sistema por quienes lo defienden. En palabras de Osorio Véliz:

(...) el arbitraje potestativo logra poner en pie de igualdad a sindicatos mayoritarios, o que abarquen un gran número de trabajadores del empleador, como a sindicatos minoritarios, o pequeños, en el marco del ejercicio de una huelga 9 .

Si partimos de que el derecho a la negociación colectiva es principalmente de titularidad del sindicato, pero es ejercido de manera

9 OSORIO VÉLIZ, Valeria. El arbitraje potestativo en la Ley de Relaciones Colectivas de Trabajo: análisis crítico y propuestas de mejora. Tesis para optar por el grado de abogada. Pontificia Universidad Católica del Perú. Julio de 2017, p. 74. Puede consultarse en:

http://tesis.pucp.edu.pe/repositorio/bitstream/handle/123456789/9262/Osorio_V\%C3\%A9liz_Arbitraje_\%20potestativo_Ley1.pdf?sequence $=1$ 
conjunta por las partes, tendremos que aceptar que el componente principal, en estricto el único, que debiera condicionar o determinar su resultado debiera ser la identidad de las mismas.

En el arbitraje potestativo, en cambio, nos encontraremos con circunstancias como que laudos similares se produzcan no ante sindicatos similares, sino ante tribunales de composición similar.

No hay negociación en la que ocurra ello. Un sistema que tienda a ese tipo de distorsiones no está constituyendo un sistema de negociación colectiva.

\section{iii. Las dificultades de aplicación demuestran las deformaciones del sistema}

Existe una verdad infrecuentemente mencionada, y que tiñe todo el sistema de arbitraje potestativo.

El elemento central a efectos de cuál sea la solución del diferendo, en lo efectivo, no es la situación de las partes, o su actuación, o sus realidades. Mucho más pesa en aquella la identidad de los árbitros que componen el tribunal arbitral.

Postulamos ya líneas arriba que cada persona tiene convicciones y vías de razonamiento que la llevarán a soluciones distintas al conflicto de intereses. Que un arbitraje de conciencia como el laboral se lleve a cabo con un set de árbitros determinado, va a llevar a que la solución sea distinta a la que habría ocurrido si hubieran sido otros los designados.

Como plantea Osorio Véliz:

Lamentablemente, este es uno de los puntos más débiles del arbitraje para conflictos laborales colectivos, dado que muchas veces la cercanía de la parte con el árbitro que eligió hace que el resultado pueda ser anticipado por cada parte. Es decir, que cada árbitro resolverá tomando la postura de la parte que lo eligió.

En el escenario descrito, el presidente del Tribunal Arbitral es identificado como el principal objetivo, dado que dependerá de él finalmente cuál será la propuesta final a adoptarse en el arbitraje, ejerciéndose sobre él una presión que -en muchos casos- es desmedida ${ }^{10}$.

El problema, como cualquier lector podrá comprender, se presenta cuando las partes tienen que designar el tribunal, y principalmente a

10 OSORIO VÉLIZ, Valeria. Op. cit., p. 41. 
quien lo presidirá, pues es este último quien en muchos casos inclinará la decisión hacia un lado, o hacia el otro, o hacia una tercera vía ${ }^{11}$.

La norma, como es natural, proporciona una salida al caso en el que los árbitros designados por las partes no se ponen de acuerdo en la identidad del presidente. El artículo 64 delega la solución a la Autoridad de Trabajo, de modo que a falta de acuerdo, ésta designa al presidente.

Durante los primeros años de la aplicación del nuevo sistema, esta designación se efectuaba por simple acto volitivo del funcionario competente.

Esto era simplemente inaceptable. La LRCT se promulgó como ruptura frente al sistema preexistente, en el cual, cuando las partes no se ponían de acuerdo, el Ministerio de Trabajo «resolvía» la negociación colectiva y determinaba los beneficios a ser concedidos a los trabajadores.

Dicho sistema devino en la virtual desaparición de la negociación colectiva como tal, durante la segunda mitad de la década de los ochenta, e inicios de la de los noventa, pues para las partes era muy simple conocer los criterios que aplicaba en un determinado momento la Autoridad Administrativa de Trabajo.

A la parte que le resultaba más cómoda dicha solución, simplemente le bastaba la inacción, el silencio, para que el procedimiento terminara con un resultado conocido de antemano y estandarizado, guiado por criterios que no solamente no eran técnicos (con todas las dificultades que respecto a esto ya hemos descrito) sino que resultaban principalmente políticos.

Si en el nuevo sistema la Autoridad de Trabajo designaba los árbitros en simple ejercicio de imperio, se retornaba en la práctica al sistema preexistente (pues el Ministerio podría nombrar como presidentes a quienes tuvieran tendencias más cercanas a sus motivaciones) pero, peor aún, derivando la responsabilidad formal a dichos terceros.

En dicho sistema original, el Estado se habría terminado convirtiendo en una especie de titiritero de la negociación colectiva, lo que a estas alturas de la historia ya no parece admisible.

11 Dada la amplitud de las facultades del tribunal, es frecuente que se haga uso abiertamente liberal de la posibilidad de atenuar posiciones «extremas» (que para serlo simplemente tienen que ser descritas como tales por el tribunal). A pesar de al menos dos pronunciamientos judiciales en los que se ha anulado laudos arbitrales por el abuso en el ejercicio de esta facultad, diríamos que su uso se presenta en la mayoría de los arbitrajes. 
Para evitarlo, el sistema fue modificado, y se pasó a un sistema de sorteo, el cual se lleva a cabo en audiencia pública, de entre un grupo de profesionales acreditados en un registro especial.

En ese grupo de personas, están quienes se puede presumir están: principalmente abogados laboralistas, y otros profesionales ligados o vinculados al campo de las relaciones laborales.

Cada uno de ellos tiene sus criterios, cada uno de ellos representará, en caso de ser designado, el componente quizás principal de la determinación o modificación de las remuneraciones y condiciones laborales de un colectivo de trabajadores, así como de la carga económica y funcional que soportará en adelante una organización empresarial.

En otras palabras, y simplificando al extremo la figura, el resultado de la negociación colectiva en nuestro país se echa a la suerte.

El problema es que difícilmente se podrá llegar a otro sistema mejor de elección. Si no es la suerte, tendrá que ser la voluntad de alguien, y ello contaminará el carácter aséptico que tendría que tener la elección. $\mathrm{Si}$, en cambio, fuera simplemente una secuencia, la elección del presidente recaería en la práctica en la parte que gatille el mecanismo en un determinado momento, si se conoce dicha secuencia, o que las partes se lancen a ciegas hacia la misma, lo que es igual que el sorteo.

De otro lado, durante el último año se lanzó una serie de propuestas de modificación de la normativa actual, de modo de corregir algunos vicios detectados en el sistema.

Así, para evitar que una parte simplemente recurra al arbitraje potestativo sin siquiera intentar acercamientos, se ha establecido periodos y número mínimo de reuniones (Decreto Supremo 009-2017-TR); para limitar el potencial daño a las empresas y el recurso fácil al medio, se ha propuesto que en arbitraje potestativo no pueda generarse la obligación de conceder bonificaciones por cierre de pliego a los trabajadores; para evitar los abusos en la facultad de atenuación, se ha planteado que dicha facultad desaparezca.

Ninguna de dichas «soluciones» lo sería en realidad. Si una parte no quiere negociar, puede sentarse dos o 17 veces con la otra, y simplemente no negociará. Si un tribunal decidido a beneficiar a un sindicato no puede integrar un cierre de pliego, el contenido real, económico, de dicho beneficio, será canalizado por el sindicato, y 
por el tribunal, hacia otros; si no se atenúa propuestas, éstas pueden devenir en situaciones realmente inmanejables.

Y es que el problema no es el arbitraje, sino la imposición. Ninguno de dichos «vicios» o desajustes lo era realmente mientras no se confirió el carácter de potestativo al arbitraje, por el sencillo motivo de que quien se sometía al mismo sabía lo que podía ocurrir, y lo calculaba previamente.

Era conocido que los tribunales tendían a atenuar en exceso para lograr la unanimidad, es decir, a literalmente trasladar una negociación de las partes a los árbitros.

Como que también era conocido el riesgo inmenso para la posición propia que suponía que la designación del presidente fuera por sorteo. Pero eso no era un problema.

Es que, finalmente, ¿existe algún inconveniente insalvable para que ello ocurra? ¿Está mal que se decida la negociación colectiva lanzando una moneda al aire, como si se tratara de elegir el lado del campo al iniciar un partido de futbol?

No está mal; está muy bien, si las partes así lo han decidido. Pero está muy mal que ello ocurra cuando tan solo una de ellas lo hace.

Todos los desajustes, los desencuentros, las irracionalidades del sistema, se perdonan y se asumen cuando los interesados los han elegido. Ninguno de ellos resulta aceptable cuando ello no ha sido así.

Lo ocurrido, como tantas veces en nuestra disciplina laboral, configura la imposición de un mecanismo que tiene validez en los gabinetes legales, pero que no goza de legitimidad entre los intervinientes de la relación sustantiva. Postulamos humildemente que esto debe ser objeto de revisión y rectificación normativa.

Lima, mayo del 2018 